\title{
Reflections on Accelerating the Transformation of Chinese Economic Growth Mode
}

\author{
Xiaoming Qiao \\ Journal Editorial Department, Yunnan Normal University, Kunming \\ 650092, Yunnan China
}

\begin{abstract}
" A number of major issues of the CPC Central Committee on the construction of socialist harmonious society " takes "significantly improve the efficiency of resource use, ecological environment improved significantly" as one of nine goals of construct a socialist harmonious society, specifically "strengthen environmental protection, people and nature are in harmony. "At present, the most fundamental problem is the extensive mode of economic growth has not fundamentally been changed, the shortage of resources and environmental pollution further increase the pressure. It will seriously restrict Chinese sustained economic growth, affecting people's lives. Therefore, we must fundamentally change the mode of economic growth, focus on improving the efficiency of resource use, reduce energy consumption, protect the environment and achieve sustainable development.
\end{abstract}

Keywords: economic growth mode; transformation; harmonious society

\section{Introduction}

The Fifth Plenary Session of the Sixth Central Committee of the Communist Party of China adopted the "CPC Central Committee on the formulation of national economic and social development of the Eleventh Five-Year Plan of the proposal" stressed: "China must accelerate the transformation of economic growth mode of Chinese land, fresh water, energy, mineral resources and Environmental conditions have seriously constrained economic development. It is necessary to conserve resources as a basic national policy, develop a recycling 
economy, protect the ecological environment, accelerate the building of a resource-saving and environment-friendly society, and promote economic development and population, resources and environment. Environmental protection and ecological problems faced by Chinese economic and social development, "he said, adding that Chinese economic and social development should be carried out in an all-round way, and that Chinese economic and social development should be carried out in an all-round way.

\section{The harm of the extensive economic growth mode}

The extensive mode of economic growth is based on the development model of "high investment, high consumption and high pollution", which leads to the depletion of many natural resources, damage the people's living environment and endanger people's physical and mental health. State Environmental Protection Administration statistics show: "At present, Chinese land area of $1 / 3$ by acid rain pollution, the main water system $2 / 5$ as inferior water, more than 300 million rural populations can not drink safe water and more than 400 million urban residents are breathing heavily polluted air."

First of all, the extensive mode of economic growth has seriously depleted the resources and posed a great threat to sustainable development. Natural resources are human-generated, naturally occurring, material energies. Natural resources are the necessary material foundation for the survival and development of human beings, and provide the basic guarantee for the clothing, food, shelter and transportation of human beings. However, any resource is limited in quantity and can not provide sufficient guarantees for the endless demands of mankind. From Chinese basic national conditions, China has 1.3 billion populations and the total population, the relative lack of per capita resources. "Chinese per capita water resources is only the world average of $1 / 4$, per capita arable land has less than $40 \%$ of the world average, oil, natural gas, copper and other important mineral resources per capita reserves are only equivalent to the world average per capita (P96), while the resources are relatively low, the utilization of resources is low, energy efficiency, industrial water recycling rate, the total recovery rate of mineral resources, and other resources.

Secondly, extensive economic growth has seriously polluted the environment and posed a great threat to our health and survival. With the development of such high-pollution, high-consumption and low-efficiency economic growth mode, the air pollution, water pollution and soil pollution have become more and more serious, and the ecological security has been seriously affected. There are more than 400 water supply shortage, of which more than 100 cities in serious water shortages, there are 360 million rural people in China do not meet the health standards of water; Chinese emissions of carbon dioxide emissions of 19.27 million tons of soot emissions of 10.13 million Ton, industrial dust emissions of 94.13 million tons, the people's health has been seriously damaged.

The above facts show that human beings in their own development process will inevitably have a negative impact on natural resources and ecological 
environment, especially in our country, a population of extremely scarce resources, environmental capacity is extremely small cases, Chinese economy If such a high consumption, high pollution, extensive development, will become the bottleneck restricting the sustainable development of Chinese economy.

\section{The obstacles encountered in the process of economic growth transformation}

Although we have recognized that Chinese modernization is facing a very serious ecological problems, put forward the strategy of sustainable development, requires transformation of economic growth, strengthen environmental protection and protection, and promote the harmonious development of man and nature. But the effect is not obvious, the formation of the edge of governance, side pollution situation. The reason, we believe that the main aspects of the following:

\subsection{The pollution control measures are lax and the local governments are not well managed}

In China, the realization of sustainable development strategy, transformation of economic growth mode, strengthen environmental protection, mainly depends on the dual role of the central government and local government. The central role is to formulate guidelines, policies, routes, draft laws and regulations, to monitor the implementation of national laws throughout the country, to monitor the country's natural environment. Its essence is to supervise the environmental protection work all over the country, and the concrete implementer is the local government. However, the local government in the specific implementation process, there are still some problems:

First, the local environmental protection forces are weak, weak awareness of environmental protection. Chinese vast territory, the number and scale of enterprises are constantly expanding and there are a large number of enterprises in the region, and local government departments with less environmental protection personnel, not enough manpower and material resources to go deep into the various enterprises to conduct an investigation, law enforcement. On the other hand, the local government's enthusiasm for environmental protection is not high. This policy-oriented, will inevitably make some local governments and officials in order to give their own fishing performance, simply the pursuit of GDP growth, while ignoring the environmental degradation caused by a series of social problems.

\subsection{The business technology is backward, production consumption is high, and resource utilization is low}

The backward production technology, the high energy consumption and the low utilization rate of resources in the production process are the important reasons for the waste of resources and ecological deterioration. 
From the resource utilization point of view, "Chinese eight energy-intensive industries, energy consumption per unit of product industry average $40 \%$ higher than the world advanced level; Chinese average water productivity of food crops is only half of the developed countries; Chinese industrial water recycling rate 15-20 percentage points lower than developed countries; In addition, the total recovery rate of mineral resources in China is about $30 \%$, lower than the advanced level of 20 percentage points; Chinese building high-performance problem is very prominent, the heating energy per unit area is equivalent to climate Close to the country 2-3 times. "

From the energy consumption point of view, "Today, Chinese steel consumption has reached about 250 million tons, close to the United States, Japan and the EU combined steel consumption, accounting for about $40 \%$ of the world's total consumption; cement consumption of about 800 million tons, Accounting for about $50 \%$ of the world's electricity consumption has exceeded Japan, ranking second in the world, just below the US Chinese existing oil and gas reserves will be less than 10 years of consumption, the final recoverable reserves can barely maintain consumption for 30 years in the copper, Iron, and other important mineral reserves, whether relative or absolute, China has no great power status .2012-2014, China will usher in the annual 2.4-2.6 million tons of iron consumption peak, the next 20 years the gap will reach 3 billion Ton; 20192023, will usher in the annual 5.3 million tons -6.8 million tons of copper consumption peak, the next 20 years the gap will reach 500 million -600 million tons; 2022-2028, will usher in the annual consumption of 13 million tons of peak Chinese crude oil reserves, production and export volume of the world's first tungsten, rare earth, antimony and tin and other minerals, because of indiscriminate digging and excessive exports, the absolute reserves have been A decrease of $1 / 3-1 / 2$, according to the existing level of protection has not more than 10 years. "

\subsection{The irrational industrial structure}

Industrial structure is the core of the national economy, is an important guarantee for coordinated development. Unreasonable industrial structure is another important factor restricting the transformation of Chinese economic growth pattern. At present, the overall trend of Chinese industrial structure is the primary industry labour surplus, the proportion of secondary industry is too large and the tertiary industry development is still insufficient. Chinese investment in the primary industry is much less than the total investment in the same period in China, making Chinese agriculture has not yet reached the scale of economy has seriously hampered the development of Chinese agriculture, affecting the improvement of peasants' living standards. The second industry is developing rapidly, the investment proportion is relatively big, but the investment mainly concentrates on the iron and steel, the cement and the real estate such high energy consumption, the high pollution profession. Moreover, with the rapid development of urbanization, the rapid development of the real estate industry has been a lot of residential area covered in this high polluting enterprise next to 
the people's physical and mental health poses a serious hazard. In line with this, high value-added products, investment in line with the requirements of new industrialization have grown slowly.

\section{Some measures to change the economic growth mode}

\subsection{Increase law enforcement efforts and change the cadre performance evaluation standards}

It is a long-term and arduous task to implement the strategy of sustainable development, transform the mode of economic growth, the overall situation of the national economy and social development, the close coordination of various departments and the broad participation of the masses. Therefore, we must rely on government management, decision-making departments of the regulation and correct guidance.

To truly achieve energy-saving emission reduction, the five small businesses (small chemical, small steel, small electroplating, small printing and dyeing, small cement) a thorough improvement, a fundamental change in economic growth, first of all to strengthen party and government leaders . Under the current leadership system, the level of economic development, the implementation of sustainable development strategy, the coordination of population, resources and environment, are largely embodied in the level of leaders. In the past cadre performance evaluation standards did not put the quality of environmental protection as an important criterion to enhance the cadre, and often value the pace of GDP development, and put aside the destruction of the environment, the waste of resources so-called economic benefits, which makes a lot of The local leading cadres of the one-sided pursuit of economic growth while ignoring the importance of environmental protection work.

\subsection{Actively promote industrial restructuring adjustment}

In the process of promoting the adjustment of industrial structure, we should pay attention to the allocation of investment structure of the industrial structure, the proportion of sustainable development should be the primary goal, increase environmental pollution control efforts to achieve economic and social development, And the harmonious development of nature as the main purpose of industrial restructuring.

First, optimize the primary industry. With the rapid development of Chinese economy, Chinese farmers have been basically solved the problem of food and clothing. However, the income of farmers in China has been growing slowly for several years, and the development is very uneven. The income gap of farmers in China is gradually widening. To solve this problem, Chinese agriculture must break the traditional structure of agricultural industry, change to the diversified and modernized agricultural industry structure, expand the market capacity of 
agricultural products, form the scale economy of agriculture, increase the income of farmers and promote the integration of urban and rural areas.

Chinese industrial structure is often the emphasis on the development of heavy industry, taking the high-pollution and high consumption of the road of development, Chinese sustained economic development constitutes a hazard. Therefore, we should focus on energy, raw materials and other basic industries, shutting down a number of large sewage, low efficiency and poor technology companies. Vigorously develop high value-added products, rapid economic growth, resource-saving enterprises, changing the extensive operation of the past, waste of resources production mode, the implementation of intensive production and take a new road to industrialization.

The tertiary industry has a wide range of business, employment opportunities and more features, vigorously develop the tertiary industry, not only to the urban low-income people to provide a broad employment channels, but also to farmers into the city, to promote the process of urbanization provided the conditions. The development of tertiary industry should be compatible with the development of the first and second industries, giving priority to the development of information industry to promote economic growth.

\subsection{Promote the development of circular economy}

The so-called circular economy is in accordance with the natural ecological material circulation mode of operation of the economic model. Recycling economy is characterized by resource conservation and recycling. Resources and environment are essential factors for economic and social development, and provide conditions and guarantees for the economic and social development, human production and life. For example, Chinese northwest region of the implementation of the "five supporting" eco-agricultural model, land-based to biogas as a link to form a farming and animal husbandry, to promote animal husbandry and animal husbandry, to promote fruit marsh, fruit and animal husbandry combined development and benign Circulation system.

Circular economy can rational use of resources, through the continuous recycling of resources, can reduce the pressure of economic growth on the supply of resources. If the energy of our country can be fully utilized, the impact of economic and social development on the demand of natural resources and the ecological environment will be alleviated and the environmental quality will be greatly improved. Only by vigorously developing the circular economy can we ensure the rapid, healthy and stable development of Chinese economy, as well as fundamentally solve the pressure of economic growth on the environment.

\subsection{Strengthen the supervisory role of media and the public}

The implementation of sustainable development strategy, change the mode of economic growth, making the harmonious development between man and nature, relying solely on the government's official power is very limited, to vigorously develop the environmental non-governmental organizations, media supervision, enhance public awareness of environmental protection, People active 
participation. The media to timely exposure, the ugly phenomenon made public, on the one hand through the newspapers, television, radio and other major media widely publicize the protection of the environment, conservation of resources, the environment and the environment. Therefore, the majority of the people to take active action, and consciously supervise, for those units exceeding the sewage, affecting the lives of enterprises to protest, to collect evidence of sewage, timely report to the local environmental protection department, to the Government to help the government efficient and timely of these acts of punishment and governance, from the source removal of pollutant emissions.

\section{Conclusion}

If we want change the mode of economic growth and promote sustainable economic and social development, we must follow the scientific development concept, correctly handle the relationship between economic and social development and ecological and environmental protection, improve the regulatory system, develop circular economy, and actively promote industrial restructuring. In the process of economic development, pay attention to the protection of the ecological environment, promoting economic, natural, social and human harmony and development under the premise of protecting the ecological environment.

\section{References}

[1] Li Yangwen. "23-year environmental protection witnessed Chinese environmental protection style". International Finance News, pp.68-70, 2015

[2] Song Deyong, Ouyang Jiang. The Characteristics of Circular Economy and Its Development. Journal of Jianghan University (Philosophy and Social Sciences), pp.87- 91, 2004

[3] Sustainable Development Strategy Research Group, Chinese Academy of Sciences. "2006 China Sustainable Development Strategy Report - Building a resource-saving and environment-friendly society". Beijing: Science Press, 3(12), pp. $18-20,2005$

[4] Feng Zhijun. "Introduction to circular economy". Beijing: People's Publishing House, pp.58- 61, 2011

[5] "Sustainable Development of Enterprise Economy". Beijing: China Environmental Science Press, pp.85-87, 2014 